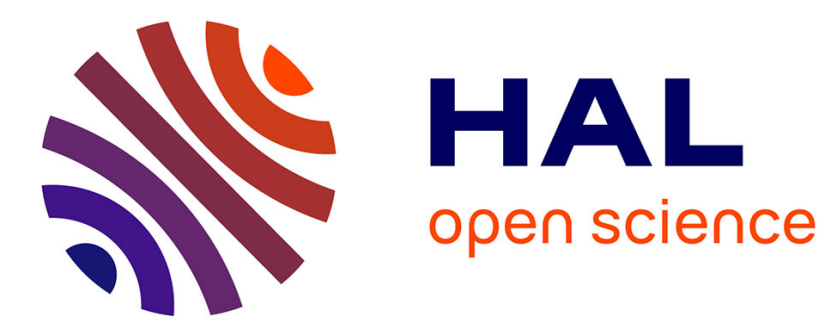

\title{
Improving adhesion strength analysis by the combination of ultrasonic and mechanical tests on single lap joints.
}

\author{
Alice Baudot, Joseph Moysan, Cedric Payan, Noëllie Ylla, Jocelyne Galy, \\ Blandine Verneret, André Baillard
}

\section{To cite this version:}

Alice Baudot, Joseph Moysan, Cedric Payan, Noëllie Ylla, Jocelyne Galy, et al.. Improving adhesion strength analysis by the combination of ultrasonic and mechanical tests on single lap joints.. Journal of Adhesion, 2014, 90 (5-6), pp.555-568. 10.1080/00218464.2013.868806 . hal-01027431

\section{HAL Id: hal-01027431 https://hal.science/hal-01027431}

Submitted on 22 Jul 2014

HAL is a multi-disciplinary open access archive for the deposit and dissemination of scientific research documents, whether they are published or not. The documents may come from teaching and research institutions in France or abroad, or from public or private research centers.
L'archive ouverte pluridisciplinaire HAL, est destinée au dépôt et à la diffusion de documents scientifiques de niveau recherche, publiés ou non, émanant des établissements d'enseignement et de recherche français ou étrangers, des laboratoires publics ou privés. 
Improving adhesion strength analysis by the combination of ultrasonic and mechanical tests on single lap joints.

Alice Baudot', 2, Joseph Moysan², Cédric Payan², Noëllie Ylla ${ }^{3}$, Jocelyne Galy², Blandine Verneret $^{4}$, André Baillard ${ }^{1}$

1. Safran Aircelle, 76700 Gonfreville l'Orcher

2. Aix-Marseille Université, LMA UPR 7051 CNRS, site LCND, 13625 Aix-enProvence, France

3. Université de Lyon, F-69003, Lyon, France; INSA Lyon, CNRS, UMR 5223, Ingénierie des Matériaux Polymères, F-69621, Villeurbanne, France

4. Safran Composite, 77550 Moissy-Cramayel

Corresponding author: Alice Baudot

\section{Abstract}

The aim of this paper is to improve knowledge about adhesion strength in single-lap joints by comparison of data from both Non Destructive Testing (NDT) and standard mechanical tests. study presents a high-frequency ultrasonic imaging of aluminum-epoxy-aluminum joints that carefully chemically prepared using two different surface treatments of the aluminum substrate: silanization and chromic-sulfuric etching. The surface energy of the treated substrate is complete set of ultrasonic data are obtained using high-frequency focused transducers. After inspection, single-lap shear tests were performed, and the mechanical strength of each joint is determined. The good correlations among the surface measurements, the mechanical tests and 
ultrasonic results are presented and discussed. The demonstration of a close correlation between ultrasonic images obtained at high frequency and the fracture surface is promising.

Keywords: Ultrasonics, lap shear, epoxy, adhesion

\section{Introduction}

Structural bonding for the automotive industry, the naval industry and aeronautics was one of the major industrial changes in the field of material assembly [1]. This major change was accompanied by the necessity of developing methodologies to assess the strength of a bonded assembly. Assessing this strength remained a real technological and scientific challenge for many years because of regular changes in the materials that were used, as well as changing standards. This challenge led to many interdisciplinary studies, as it involved both material science and mechanical science. The question of how an assembly should be mechanically tested has produced dozens of different mechanical tests. Concurrently, finite-element modeling offered new possibilities for understanding the effective mechanical strength of a structure and the impacts of many parameters (e.g., thickness, roughness, and stress concentration) and for attempting to predict cohesive or adhesive rupture [2].

Structural bonding created specific challenges for NDT science, as well. As bonding assemblies most of the time the result of an innovative process, material parts often possessed new properties and required the adaptation of NDT methods or the development of new ones [3]. The of adhesive bonding in primary structures has been limited by the lack of non-destructive testing procedures capable of guaranteeing the reliability of the joint. To date, no reliable NDT test for adhesion strength of a bond has been developed. At present, this problem is addressed by strict of the adherend-surface-preparation procedures [3]. In comparison with classical NDT methods previously developed for weld testing, the NDT testing of bonded assemblies presents new as material parts can have very different thicknesses due to the finer thickness of the bond layer. Ultrasonic and acoustic methods are the approaches that have been most commonly pursued early stages of structural bonding applications [3]. 
The field of NDT applications is continuously expanding; they are used for assessing the initial manufacturing quality of the bonding process, for in-service testing and for assessing the quality of bonding subject to aging degradation. Three classical defects are investigated [3, 4]:

a) complete voids, disbonds or porosity

b) poor adhesion (a weak bond between the adhesive and one or both adherends)

c) poor cohesive strength (a weak adhesive layer)

This study aims to propose advances in NDT techniques for the poor-adhesion case. Poor adhesion is a reduction in the strength of the bond between the adhesive and the adherend. It is extremely difficult to detect using classical ultrasonic techniques because the bond strength is governed by a layer thinner than a conventional ultrasonic wavelength. By preference, a highfrequency transducer should be used for signal analysis [5]. Severe cases in which the poor adhesion tends to zero are commonly termed kissing bonds or, alternatively, zero-volume disbonds [6]. This form of poor adhesion stands between the poor-adhesion case and the wholly disbonded case. Numerous ultrasonic testing solutions, have been developed for this specific case including non-linear acoustics [5,7-9] but also guided waves [10-11]. Alternative solutions are also in development, such as Digital Image Correlation [12].

One of the obstacles to the development and demonstration of an acoustic method capable of quantifying the adhesive strength of a bonded joint is the absence of perfect reference samples full knowledge of their assembly. Multiple solutions have been proposed in the past, and still are currently to create reference samples for NDT testing. Defects can be artificially created by foreign part at the interface between two parts [13] or by modifying the bond itself by release agent [14] or by incorporating particles [15-16]. To study the adhesion strength, the most appropriate approach would be to vary the surface preparation or the surface treatment [17]. parameters can modify the bond strength, so the true difficulty is to exactly reproduce the same preparation steps in the same environment [18]. More rarely, some studies use a chemical obtain imperfections similar to those created by pollution during industrial processes [19]. 
way to produce variable adhesion is to compress a bond; this case is representative of drykissing bonds [7].

The single-lap shear joint is the most widely studied type of adhesive joint in the literature. The manufacture of this joint is relatively easy, and the corresponding test requires a classic tensile testing machine. Many corresponding standards have been developed in industry, such as the ASTM D1002, the popular standard test method for evaluating the apparent shear strength of single-lap-joint adhesively bonded metal specimens by tension loading, or the European Standard EN 2243-1. Adhesive-lap-joint shear-strength tests do not create perfect shear solicitation, and other physical factors are uncertain, such as the overlap length and the bondline thickness [17]. Stress concentrations should also be taken into account for accurate mechanical analysis. The form of the adhesive edges greatly influences the shear-stress concentrations. Appropriate geometries were proposed to improve mechanical analysis by reducing edge effects [20]. This joint geometry is chosen for our study because it also enables a simple NDT evaluation using through-transmission ultrasonic testing. In the following, the experiments are described, and the results are presented and discussed in detail. Conclusions are proposed regarding the evaluation of variable adhesion on single-lap shear joints using high-frequency ultrasonic analysis.

\section{Experimental methods}

\subsection{Materials}

The adhesive formulation is based on a two-component epoxy system. Diglycidyl ether of bisphenol A (DGEBA, DER 332, Dow Chemicals, Paris Saint Denis, France) with an epoxy equivalent weight of $171-175 \mathrm{~g} / \mathrm{eq}$ is cross-linked with a cycloaliphatic amine hardener, isophorone diamine (IPD, Aldrich, Saint-Quentin Fallavier, France). The epoxy and the amine are mixed at room temperature, at a stoichiometric ratio aminohydrogene/epoxy equal to 1 ; the mixture is degassed to avoid air-bubble formation in the adhesive bond. $\gamma$ glycidoxypropyltrimethoxysilane $(\gamma-\mathrm{GPS})$ is obtained from Aldrich (Saint-Quentin Fallavier, France). 
The chemical structures of both components are given in Table 1.

The metallic substrate is an aluminum alloy, A2024, in the form of $1.6 \mathrm{~mm}$ thick sheets.

\subsection{Sample preparation}

The aluminum sheets are cut to $100 \mathrm{~mm} \times 25 \mathrm{~mm}$, and their surfaces are cleaned and treated before bonding to eliminate surface contamination and to promote different adhesion strengths. The following two surface treatments are employed prior to the adhesive bonding of the lapshear test samples:

* Silane treatment (Si). There are four steps in this treatment: i) solvent degreasing with a tissue soaked in isopropanol, ii) alkaline cleaning by immersing the specimens for $10 \mathrm{~min}$ in a Sococlean (Socomore, Vannes, France) A3431 solution $(\mathrm{c}=10 \%)$ heated to $45{ }^{\circ} \mathrm{C}$ followed by rinsing in water, iii) alkaline etching by immersing the specimens for $2 \mathrm{~min}$ in a solution of $40 \mathrm{~g} / \mathrm{l}$ $\mathrm{NaOH}+10 \mathrm{~g} / \mathrm{l}$ sodium glucoheptonate heated to $40{ }^{\circ} \mathrm{C}$ followed by rinsing in water and iv) silanization by immersing the specimens for $10 \mathrm{~min}$ in a $1 \mathrm{wt} \%$ solution of GPS in distilled water; prior to immersion, the $\mathrm{pH}$ of the solution is adjusted to 5 using acetic acid, and the solution is stirred at room temperature for 1 hour for the hydrolysis of the methoxy groups. The silane-treated specimens are heated for 1 hour at $93{ }^{\circ} \mathrm{C}$ in an oven to allow condensation reactions [21].

* Chromic-sulfuric acid treatment (CS). There are three steps in this treatment i) degreasing the specimens with acetone, ii) immersing them in a water solution $(\sim 300 \mathrm{~g} / \mathrm{l} \mathrm{H} 2 \mathrm{SO} 4, \sim 30 \mathrm{~g} / \mathrm{l} \mathrm{CrO} 3$, $\sim 0.5 \mathrm{~g} \mathrm{Cu}, \sim 10 \mathrm{~g} \mathrm{Al}$ ) heated at $65{ }^{\circ} \mathrm{C}$ for $15 \mathrm{~min}$, and iii) rinsing them in distilled water and drying them in an oven for $30 \mathrm{~min}$ at $60^{\circ} \mathrm{C}$.

After the surface treatment, the aluminum pieces are assembled into single-lap shear joints with overlap length of $12.5 \mathrm{~mm}$. The lap-shear geometry is illustrated in Fig. 1. A specific metallic designed to prepare the samples with a given thickness. This mold allows the simultaneous of seven specimens. The mold is placed under a press, and a contact pressure of 2.2 bars is 
then the samples are cured for 1 hour at $80{ }^{\circ} \mathrm{C}$, followed by curing for 2 hours at $180{ }^{\circ} \mathrm{C}$. This cycle fully cured the DGEBA-IPD adhesive.

\subsection{Surface energy}

The surface energies of the aluminum substrate with and without surface treatment are determined from contact angles (CA) using a GBX Digidrop contact-angle goniometer following the Owens-Wendt method [22]. The average CAs are obtained by measuring the contact angles of at least six drops each for two probe liquids, water and diiodomethane.

\subsection{Mechanical testing}

The samples are tested following EN 2243-1, using a universal testing machine (MTS,Eden Prairie, Minessota,USA) at a constant crosshead speed of $0.1 \mathrm{~mm} / \mathrm{min}$. The joint adhesive strength is calculated using the following formula:

$\tau=\frac{P_{\max }}{A}$

where $\tau$ is the adhesive strength in MPa, $\mathrm{P}_{\max }$ is the maximum load at fracture in Newton, and $\mathrm{A}$ is the average cross-sectional area in $\mathrm{mm}^{2}$. Lap-shear-strength data are obtained, and the corresponding standard deviations (std) are calculated.

\subsection{NDT characterization}

Each sample is tested by the immersion technique using two focused Panametrics V376 NDT, Waltham, MA, USA) transducers with a diameter of $12.7 \mathrm{~mm}$ and a focal distance of The experiment is performed in a water tank with two motorized arms. Each arm has five axes. The experimental set-up is piloted by the software UTWIN (Mistras, Paris, France). Fig. 2 presents the experimental set-up for the normal-incidence transmission mode. The transducers' theoretical central frequency is $30 \mathrm{MHz}$. They have been characterized with a hydrophone to the real acoustic field. The real $-3 \mathrm{~dB}$ bandwidth ranges from $14 \mathrm{MHz}$ to $22 \mathrm{MHz}$. The measured diameter of the focal zone is $0.63 \mathrm{~mm}$. 
The full bandwidth is very large (from 0 to $30 \mathrm{MHz}$ ), and as a consequence, we obtain short signals with a duration of two periods. This enables the separation of the two surface echoes, but the epoxy layer is too thin to create separated echoes (Fig. 4 and Fig. 6).

A complete set of ultrasonic signals with both transmitted and reflected signals is obtained. The $\mathrm{C}$-scan images (X, Z cartography) obtained in the transmission mode are the most informative for the discussion presented in section 4 . The displacement steps along both the $\mathrm{X}$ and $\mathrm{Z}$ axes for the C-scan are $0.2 \mathrm{~mm}$, allowing the complete recovery of the focal width.

\section{Results and discussion}

3.1. Effect of the surface treatment on the surface energy of the substrate

The contact angles and the calculated surface energies are reported in Table 2 for the asreceived substrates as well as the silane-treated and sulfochromic-treated aluminum substrates. The surface energy of the as-received A2024 has been found to be equal to $50 \mathrm{~mJ} / \mathrm{m}^{2}$. This value is in agreement with the data published in the literature [23]. The surface energy of the GPSsilanized aluminum surface is similar to that of the as-received aluminum. Moreover, the polar and non-polar contributions are the same. However, the surface is modified because the protocol used in this work has proven to be effective in causing the condensation of silanol groups on the Al surface [24]. Finally, the sulfochromic treatment leads to a higher surface energy, equal to 72 $\mathrm{mJ} / \mathrm{m}^{2}$; this increase is mainly attributed to the increase of the polar component.

\subsection{Adhesive properties}

Protocols for the two surface treatments and the preparation of the lap-shear specimens have validated using preliminary tests. The optimization of the physical-chemistry protocol has been achieved over 28 samples. The present study focuses on the samples (four samples from the silanization set $(\mathrm{Si})$ and three samples from the chromic-sulphuric set $(\mathrm{CS})$ ) that have been both ultrasonic $\mathrm{C}$-scan and mechanical tests. The results from the mechanical measurements are 
summarized in Table 3 for the two adherend treatments, silanization and chromic-sulfuric best adhesive strength has been obtained for the chromic-sulfuric surface treatment. At the end test, joint failure has been observed. In all cases, the failure mode is adhesive, sometimes with more jumps of the fracture from one interface to the other or with some adhesive remaining on the aluminum substrates.

\subsection{Ultrasonic testing results}

Each adhesive joint sample tested using the transmission method produces a C-scan of the bonded area. Our first goal is to verify the quality of the joint. Indeed, before making a prediction regarding the adhesion strength, it is important to assess the joint homogeneity. Cscan images of the samples Si-1 and CS-2 are presented in Fig. 3. and Fig. 5.

A first qualitative observation can be done as images textures are very different. For the sample Si-1 (Fig.3) large homogeneous areas with little differences in amplitudes are observed. In these large areas some localized defects are also present probably due to large gas entrapment as our bond is too liquid. Gas entrapment is a true difficulty for manufacturing adhesive joints and resulting voids should be taken into account for modes of failures [25]. The epoxy is degassed during 210 seconds using UIP1000hd device (Hielscher, Teltow, Germany) [26]. For the CS-2 sample the image texture, corresponding to ultrasonic amplitude distribution, is more heterogeneous and the spatial scale of the distribution is lower. The texture aspect could can be created by small voids distributed on all the joint surface. The adherend surface roughness contributes also to the texture aspect of C-scan images. As the transmission method is used, if the joint is properly bonded, the received signal should high amplitude; in the opposite case, if there is a defect involving the presence of air, the the signal should be very low. A-scan data has been recorded at various locations $(\mathrm{X}, \mathrm{Z})$ for each sample. The obtained results are presented in Fig. 4 and Fig. 6, which correspond to samples one the silane set ( $\mathrm{Si}-1)$ and the second of the chromic-sulfuric set (CS-2), respectively. The first echo corresponds to the direct travel of the ultrasound through the first aluminum plate, the joint and 
second aluminum plate. The second echo corresponds to the same travel path plus a round trip aluminum.

All images have been obtained with the same transducer settings. In area 1 of sample Si-1, the amplitude is very low (dark blue), which allows us to define the amplitude threshold below which the joint is considered not bonded. The corresponding threshold is $0.45 \mathrm{mV}$; thus, we can calculate the size of the bonded area and the size of the disbonded one, if any. The C-scan analyses have been conducted with MATLAB. The surface size of the adhesive joint is first visually defined. This surface is represented in Fig. 4 and 6 by the bold rectangle. Next, the size of the bonded area is automatically calculated depending on the threshold value. Thus, for sample $\mathrm{Si}-1$, the surface of the joint is $234.6 \mathrm{~mm}^{2}$, the bonded area is found to be $211.3 \mathrm{~mm}^{2}$, and the disbonded zone is $23.2 \mathrm{~mm}^{2}$. For sample CS-2, the surface of the adhesive joint is $273.7 \mathrm{~mm}^{2}$, and there is no disbonded surface. Considering the geometry of the specimens (Fig. 1), the theoretical bonded area should be equal to $312.5 \mathrm{~mm}^{2}$; however, the epoxy formulation used has a very low viscosity, and some leaks may occur in the joint. These leaks are the origin of the smaller-than-expected measured bonded area and of the observed defects.

\subsection{Correlation between mechanical tests and NDT}

This section presents the correlation between the mechanical tests and the ultrasonic tests. To for a link between the mechanical strength and the bonded surface area, a plot representing the surface area as a function of the failure load is shown in Fig. 7. Two different populations are set CS has higher failure strengths and greater bonded surface areas than set $\mathrm{Si}$. Not simple linear relation exists between the bonded area and the mechanical strength [3]. It is in a single-lap shear test, the eccentricity of the tensile axis results in peel and transverse stress distribution is highly non-uniform, so the strength is much more sensitive to the integrity some areas of the joint than to others. Therefore, measurement of the bond area, without taking localization of this bonded area into account, does not necessarily provide a linear correlation strength. Literature indicates that the presence of large defects may not modify the ultimate 
there are localized in the middle of the joint. This behavior depends also of the ductility of the adherend [27].

With the knowledge of the real bonded area, we can evaluate a more accurate joint adhesive strength using formula (1). Table 4 presents the corrected strengths. It reveals that the silane treatment may yield the same adhesion strength as the chromic-sulfuric acid treatment, as the average strengths are very similar. It also reveals that in this study, the silane treatment produces less reproducible results. Such information is not evident from only the results obtained with the mechanical tests (see Table 3). Using strength results, no significant difference arises between the two surface treatments. It is due to the presence of voids identified through the ultrasonic data set. Moreover, additional interesting correlations between C-scan images and the fracture surface are described below.

The mechanical tests continue until failure of the samples. Therefore, at the end of these tests, the fracture surfaces can be optically observed (Fig. 8 and 9). A strong similarity in shape can be observed between the visible features of the fracture surfaces and the ultrasonic C-scans. Traces of epoxy are indicated with the letter E on the fracture photographs (Fig. 8 and 9), while apparent aluminum surfaces are indicated with Al. Various indications of likely failure modes are thus obtained:

- adhesive failure when the photographs give $\mathrm{Al}-\mathrm{E}$ or $\mathrm{E}-\mathrm{Al}$ indications

- cohesive failure when the photographs give E-E indications

- defect presence when the photographs give $\mathrm{Al}-\mathrm{Al}$ indications

The adhesive failure mode is the most commonly observed in Fig. 8 and 9. It is the expected failure mode, as the surface treatment is the variable parameter in this study. Also as expected, the cohesive failure mode is not observed. The third case, the presence of one or more defects, is apparent in zone 1 (defined in Fig. 3 above) of sample Si-1, which is consistent with our analysis of signal 1: there is no ultrasound transmission. This case is not expected and is attributed to an excessively fluid epoxy adhesive. 
The position of the defect in zone 1, where there is no stress concentration, could explain why this sample demonstrates a similar strength to the other samples during the shear test despite the presence of a large defect.

The pictures of the fracture surfaces and the C-scans corresponding to samples Si-1 and CS-2 are presented in Fig. 8 and Fig. 9. The bonded area is more homogeneous for sample CS-2. The small, circular, weakly adhesive areas that are visible on the C-scans (darker areas of the image) are also apparent on the fracture surfaces.

\section{Conclusion and prospects}

This study shows how the combination of mechanical and ultrasonic NDT methods can provide additional information in the view of a better understanding of adhesion strength. For the material aspect of this challenge, the use of different surface treatment is the preferred solution. Using a high-frequency C-scan, it is possible to obtain a corrected value for the bonded surface area, allowing the proper evaluation of the adhesive strength. It is also shown that these ultrasonic images exhibit a notably good correlation with the fracture surfaces obtained after failure.

Efforts in progress aim at improving the $\mathrm{C}$-scan method using higher frequencies as well as the epoxy adhesive which will be more viscous. It should allow separating echoes in ultrasonic data, increasing the information available such as speed of sound and attenuation. A complementary approach using $\mathrm{C}$-scan images associated with a detailed analysis of the stress concentrations would greatly help multidisciplinary studies concerning adhesion strength.

\section{Acknowledgments}

The authors wish to thank Erwin Taviot (Aix-Marseille Université) for his contribution to the ultrasonic experiments, and Professor R. Adams for useful discussions and comments about this The collaboration with Aircelle and Safran Composites is gratefully acknowledged. This work was 
supported under the PRC Composites, French research project funded by DGAC, involving Group, ONERA and CNRS. 


\begin{tabular}{|c|c|c|}
\hline Name & Chemical structure & Molar mass $(\mathrm{g} / \mathrm{mol})$ \\
\hline DGEBA & $\mathrm{O}$ & 348 \\
\hline IPD & & 170 \\
\hline$\gamma$-GPS & $\mathrm{H}_{\mathrm{OCH}_{3}}^{\mathrm{O} \mathrm{CO}-\mathrm{SH}_{3}}$ & 236 \\
\hline
\end{tabular}

Table 1 : Chemical structure of monomers 


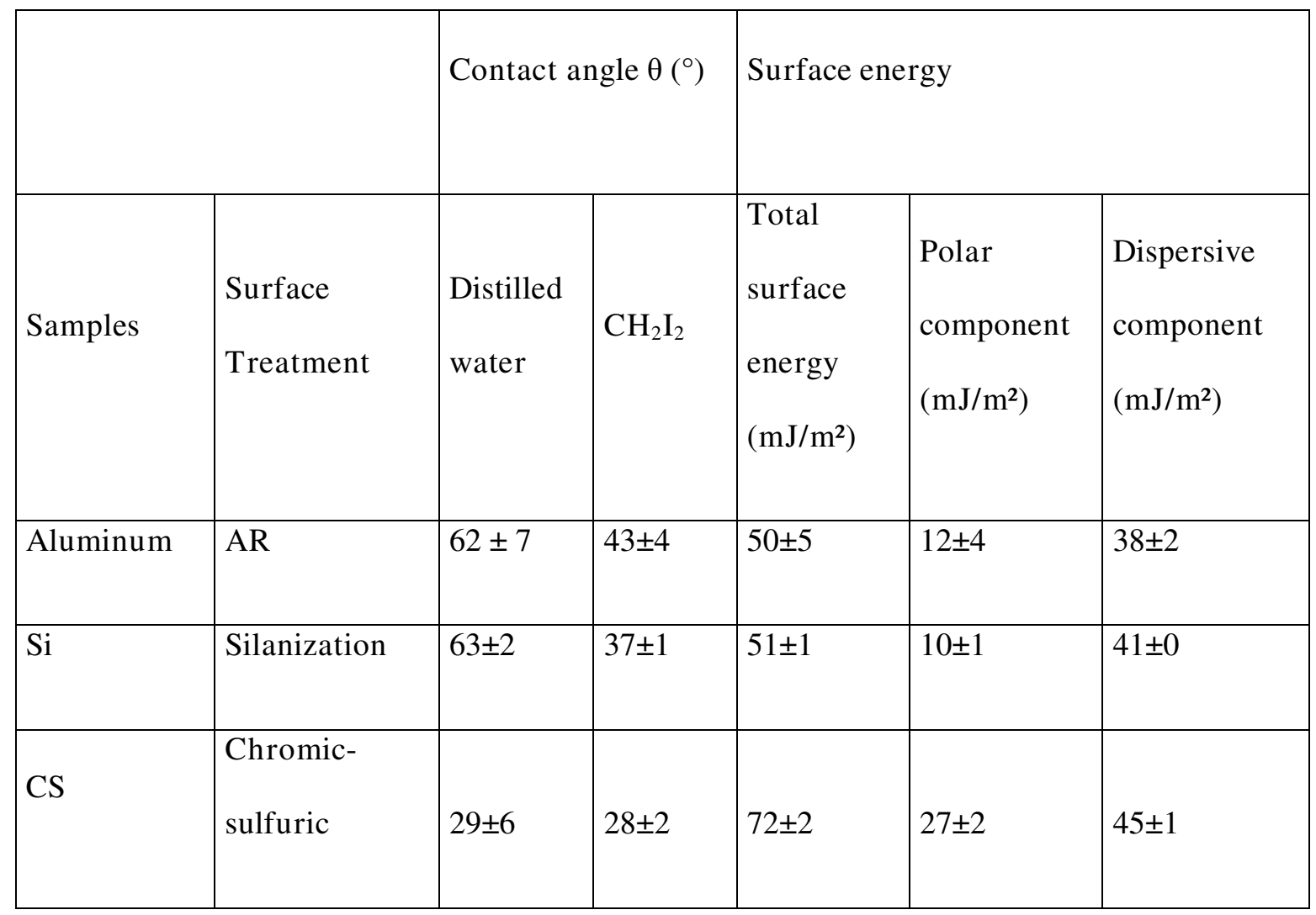

Table 2 : Surface energy of the substrates 


\begin{tabular}{|c|c|c|c|}
\hline Final Sets & Surface & Mean & Number of samples \\
& treatment & $\tau(\mathrm{MPa}) / \mathrm{std}(\mathrm{MPa})$ & \\
\hline $\mathrm{Si}$ & Silanization & $9.2 / 0.7$ & 4 \\
\hline $\mathrm{CS}$ & Chromic- & $12.6 / 0.7$ & 3 \\
& sulfuric & & \\
\hline
\end{tabular}

Table 3 : Mechanical results 


\begin{tabular}{|c|c|c|c|c|}
\hline Final Sets & Surface treatment & Mean & Mean & Number of \\
& & $\begin{array}{c}\text { Bonded area } \\
\left(\mathrm{mm}^{2}\right)\end{array}$ & $\tau(\mathrm{MPa}) / \mathrm{std}(\mathrm{MPa})$ & samples \\
\hline $\mathrm{Si}$ & Silanization & $222.3 / 51.5$ & $13 / 3.1$ & 4 \\
\hline $\mathrm{CS}$ & Chromic-sulfuric & $281.5 / 8.20$ & $14.0 / 1$ & 3 \\
\hline
\end{tabular}

Table 4 : Mechanical results corrected for the bonded area measured with the UT throughtransmission method 


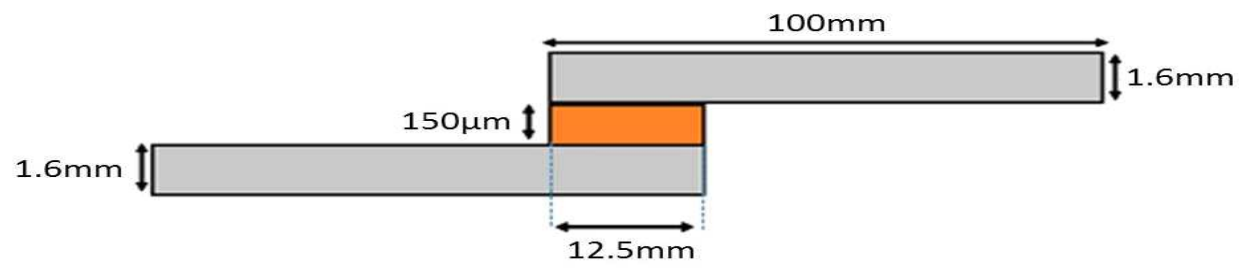

Fig. 1 : Geometry and dimensions of lap joint 


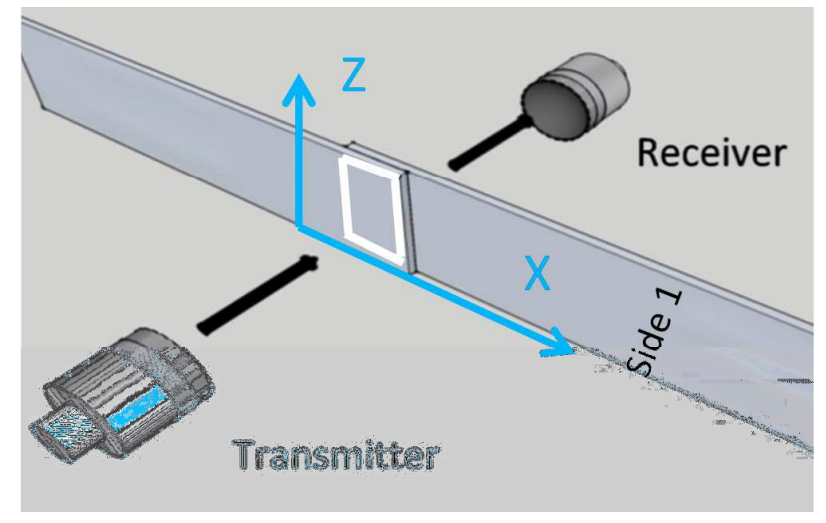

Fig. 2 : Normal-incidence-transmission experimental set-up 


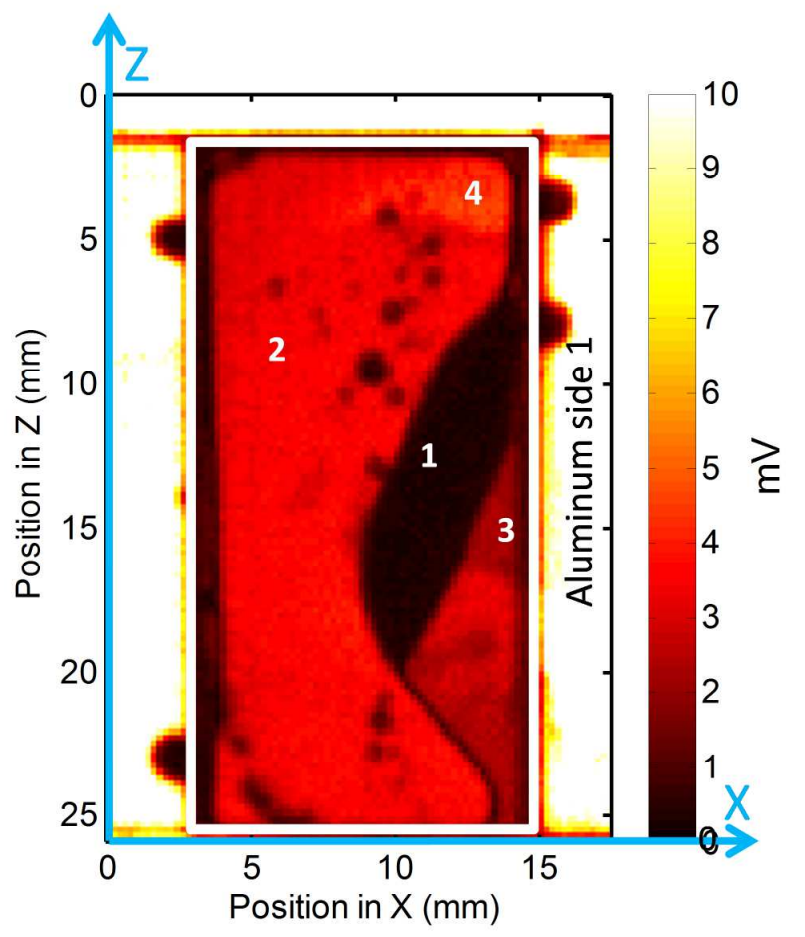

Fig. 3 : C-scan of sample Si-1 (amplitude in milivolts) 


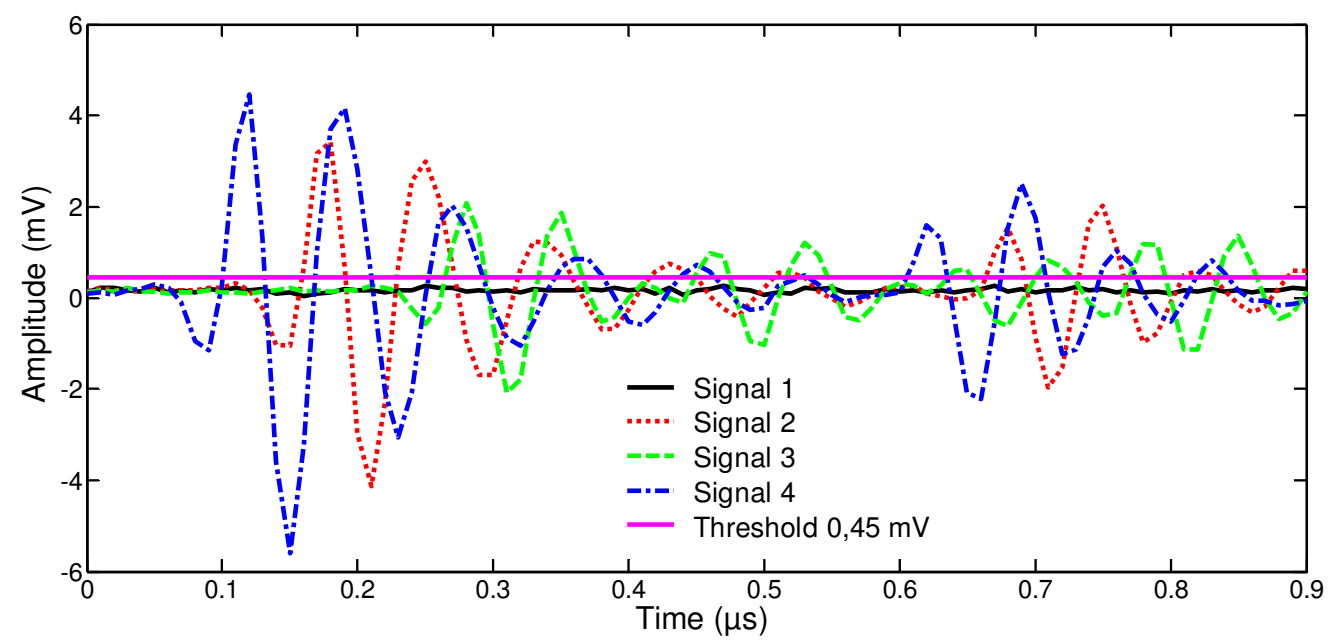

Fig. 4 : Sample Si-1: A-scan data from different areas 


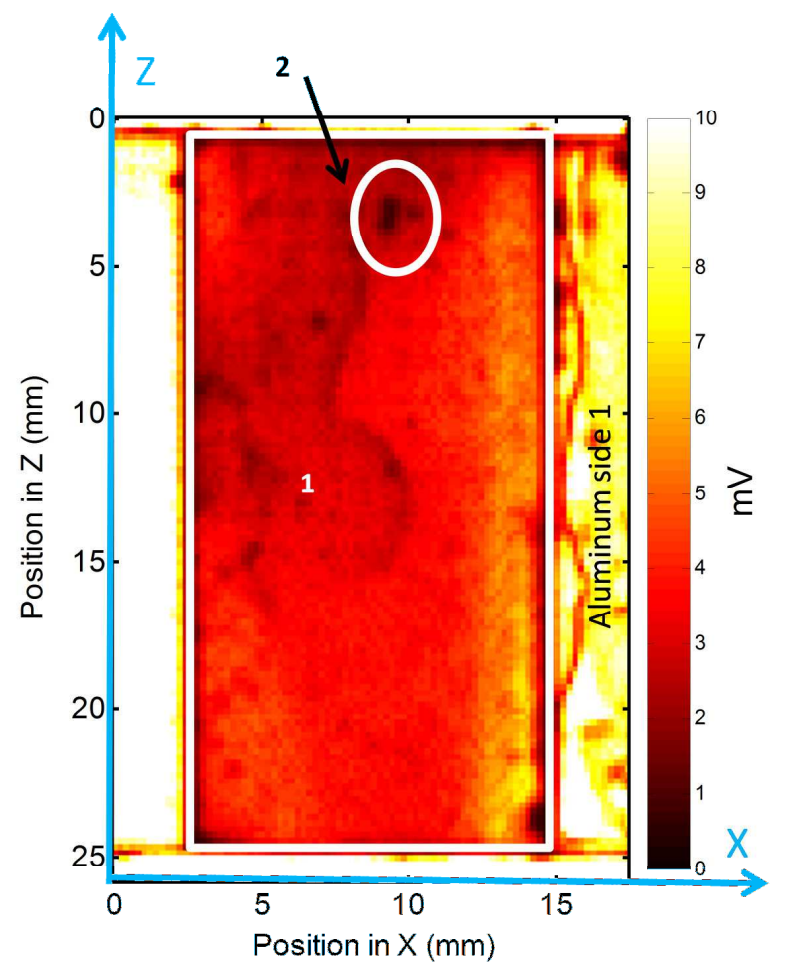

Fig. 5 : C-scan of sample CS-2 (amplitude in milivolts) 


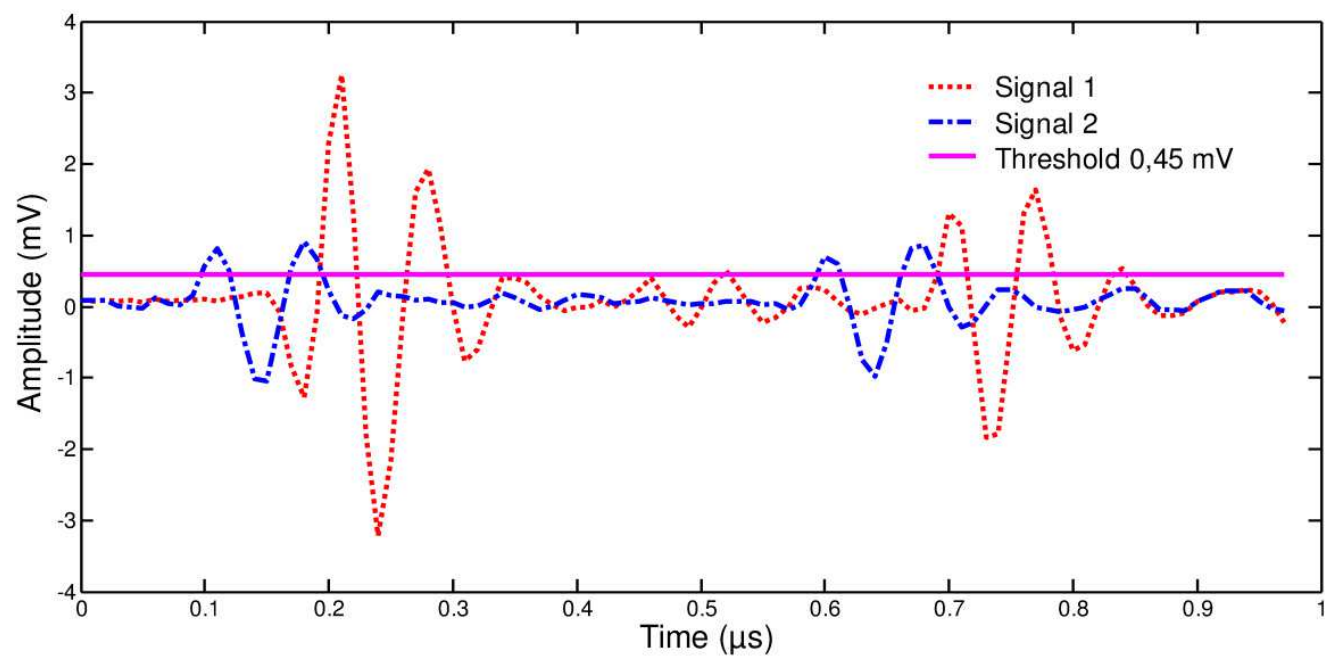

Fig. 6 : Sample CS-2: A-scan data from different areas 


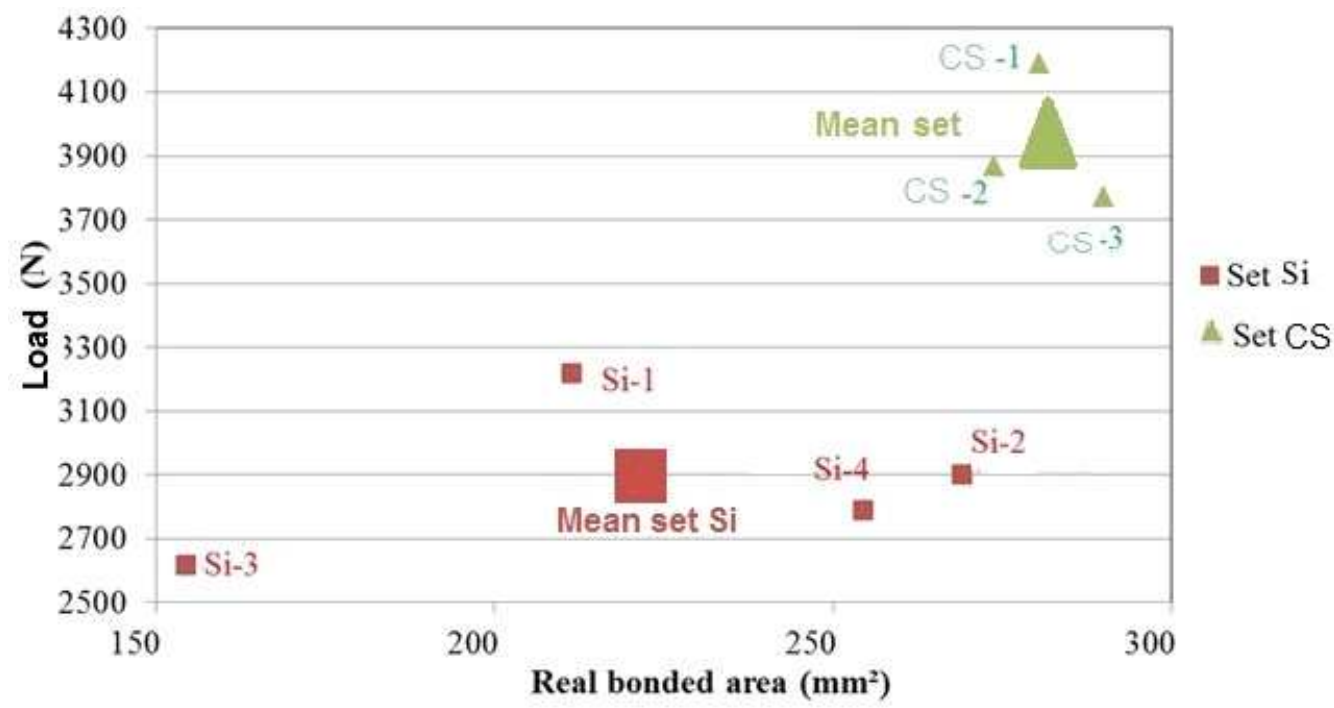

Fig. 7 : Bonded area versus load 


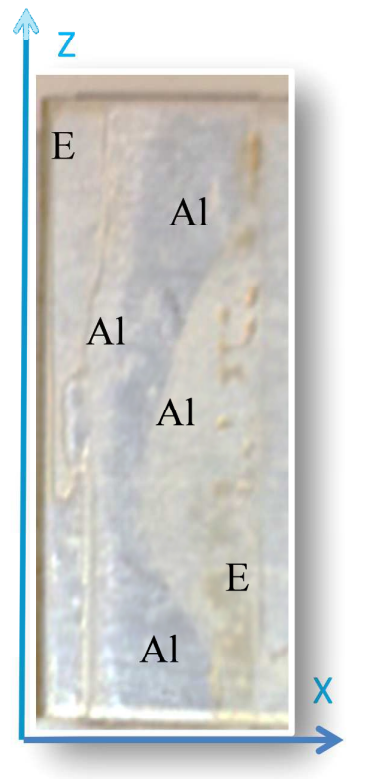

Picture of side 1

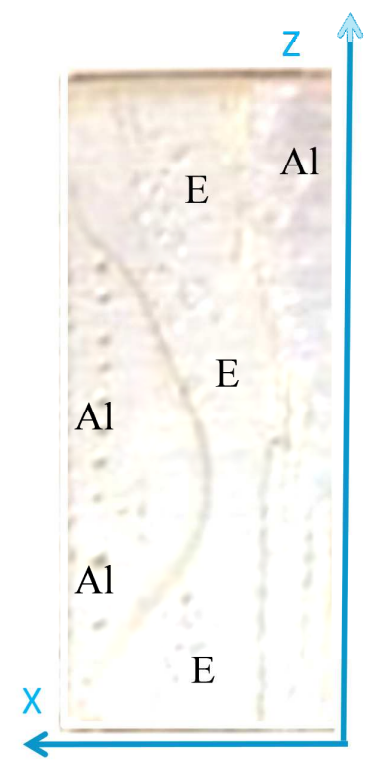

Picture of side 2

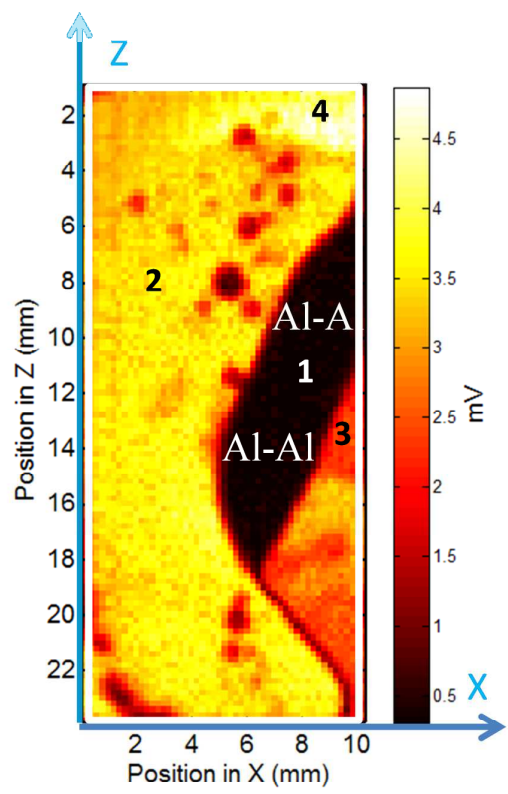

C-scan

Fig. 8 : Sample Si-1: fracture surfaces and C-scan (amplitude in mV) 


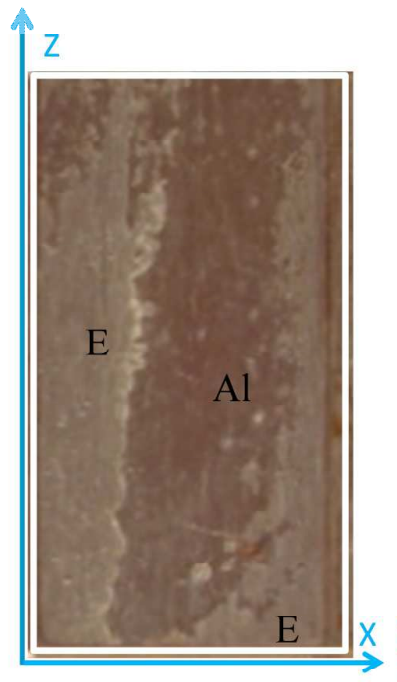

Picture of side 1

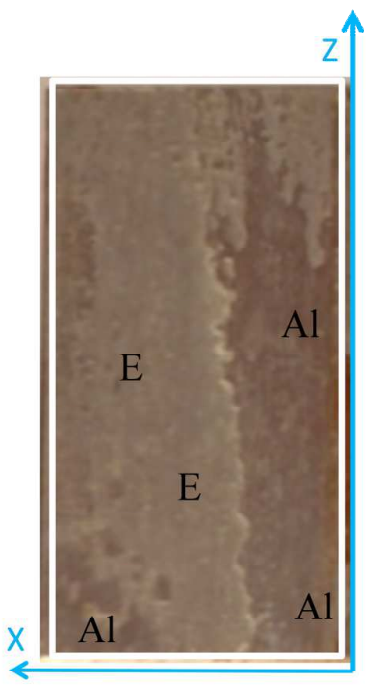

Picture of side 2

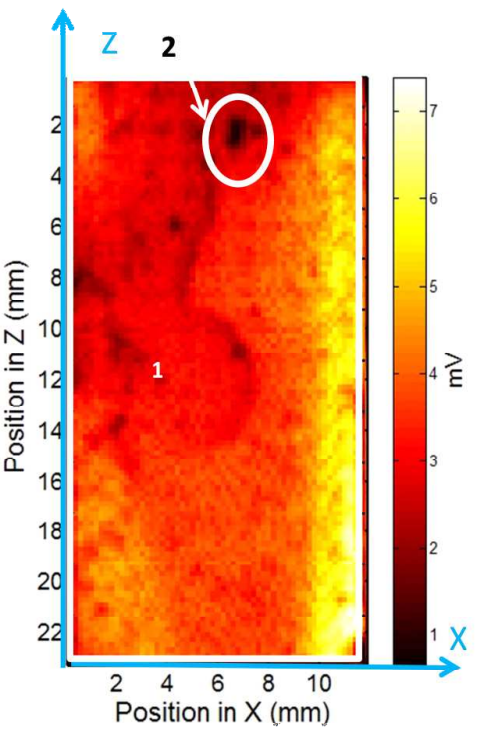

C-scan

Fig. 9 : Sample CS-2: fracture surfaces and C-scan (amplitude in $\mathbf{m V}$ ) 
References

[1] R D Adams, (Woodhead Publishing Ltd., University of Bristol, UK, 2005)

[2] Lucas Filipe Martins da Silva and Andreas Öchsner, (Springer-Verlag , Berlin Heidelberg, Germany 2008)

[3] C.C.H. Guyott, P. Cawley, R.D. Adams, Journal of adhesion, 20, 129-189 (1986)

[4] Michaloudaki, M.; Lehmann, E. \& Kosteas, D. , Journal of Adhesion and Adhesives, 25, 257$267(2005)$

[5] R. Adams, B. Drinkwater, Journal of Materials and Product Technology, 14, 385-398,(1999)

[6] P.B. Nagy, J. Adhesion Sci. Technol, 5, 619-630 (1991)

[7] C.J. Brotherhood, B.W. Drinkwater, S. Dixon, Ultrasonics, 41, 521-529 (2003)

[8] Bockenheimer C, Fata D, Possart W, Rothenfusser M, Netzelmann U and Helmut Schaefer, International Journal of Adhesion and Adhesive, 22, 227 - 233 (2002)

[19] D. Yan, B.W. Drinkwater, S.A. Neild, NDT \& E International, 42, 459 - 466 (2009)

[10] M.J. Santos, J. Pardigao, P Faia, The Journal of Adhesion, 84 ,421-438(2008)

[11] B. Le Crom, M. Castaings, Journal of Acoustics Society of Am., 127, 2220-2230 (2010)

[12] R.L.VijayaKumar, M.R.Bhat, C.R.L.Murth, International Journal of Adhesion Adhesives, 42, 60-68 (2013)

[13] N.R. Smith, J.R. Kollgaard, L. Dickinson, Sampe Journal, 47, 25-31(2011)

[14] R.L. Vijaya Kumar, M.R. Bhat, C.R.L. Murthy, Ultrasonics, 53,1150-62 (2013) 
[15] Richard E. Challis, Andrew K. Holmes, John S. Tebbutt, and Richard P. Cocker , J. Acoust. Soc. Am., 103, 1413-1420 (1998)

[16] M. May, H.M. Wang, R. Akid, Int. Journal of Adhesion \& Adhesives, 30, 505-512 (2010)

[17] Lucas F M da Silva, R J C Carbas, G W Critchlow, M A V Figueiredo and K Brown, International Journal of Adhesion and Adhesives, 29, 621-632 (2009)

[18]A. Baldan Journal of materials science, 39, 1- 49 (2004)

[19] M.U. Jastrzebski,, A.N. Sinclair, D.D. Raizenne, J.K. Spelt, International Journal of Adhesion \& Adhesives, 29, 372-379 (2009)

[20] J.Y. Cognard, R. Créac'Hcadec, J.Maurice, International Journal of Adhesion \& Adhesives, 31, 715-724 (2011)

[21] Abel ML, Allington RD, Digby RP, Porritt N, Shaw SJ, Watts JF. Int J Adhes Adhes, 26, 2$15(2006)$

[22] D.K owens, R.C. Wendt, J. Appl. Polym. Sci, 13, 1741-1747 (1969)

[23] A.F. Harris, A. Beevers, International Journal of Adhesion \& adhesives, 19, 445-452 (1999)

[24] Ramazan Kahramana, Mehmet Sunar, Bekir Yilbas , Journal of Materials Processing Technology, 205, 183-1892008)

[25] Lucas F M da Silva, R.D. Adams, M. Gibbs, International Journal of Adhesion and Adhesives, 24, 69-83 (2004)

[26] O.A. Kapustina, (LD. Rosenberg, Plenum press New-York, 1973 )

[27] E.F.Karachalios, R.D.Adams, LucasF.M.da Silva, International Journal of Adhesion \& Adhesives, 45, 69-76 (2013) 